\title{
The Effect of Microeconomic Factors on Business Models in Fintech Industry
}

\author{
Rosita Zvirgzdina \\ Turiba University \\ Riga, Latvia \\ rosita@turiba.lv
}

\author{
Helena Skadina \\ Turiba University \\ Riga, Latvia \\ helena.skadina@gmail.com
}

\author{
Iveta Linina \\ Turiba University \\ Riga, Latvia \\ iveta.linina@turiba.lv
}

\begin{abstract}
The variety of financial technology (FinTech) companies and their activities poses heterogeneity in the business models of them. Not only the business environment has been changing rapidly, the financial services sector influences and triggers changes as well. And it is hard to determine whether and which changes influence the business model disruptively and which evolutionary. To enable management decision making easier, methodology for identification of possible microeconomic risks and their influence on the current activity and the whole business model of the company has to be shaped accordingly. The aim of this research is to find out what and how microeconomic factors affect business modelling of the FinTech companies. In this research the authors used a continuous comparative analysis method as well as content analysis method [1]. In interviews, experts were asked to assess the significance of specific microeconomic factors by using the Likert's scale. As a result of the research, the difference of the influence as well as their dependencies and modifications on business modelling was determined. This result forms the basis for conclusions about the most important microeconomic impact factors, the areas of their influence and possible consequences that affect business modelling of the FinTech company.
\end{abstract}

Keywords—business model, impact factor, microeconomic, FinTech.

\section{INTRODUCTION}

Global investment in financial technology (FinTech) ventures tripled to $\$ 8$ billion in 2018 [2] and clearly signify that the digital revolution has arrived in the financial services sector. The established financial services players are starting to take bold steps to engage with emerging innovations [3]. Young companies exploit new technology and this enables them to be global without having big assets. They can develop very fast by buying in services as and when they need them [4]. In just a few short years, Fintech companies have defined the direction, shape, and pace of change across almost every financial services subsector. Customers now expect seamless digital onboarding, rapid loan approvals, and free personto-person payments - all innovations that Fintechs' made popular. And while they may not dominate the industry today, Fintechs' have succeeded as both standalone businesses and vital links in the financial services value chain [5]. Fintech is primed to have an impact. There are pockets of efficiency that could significantly move the needle in mainstream banking. Data, Security, Analytics, and Regulation are the four key areas of action [6]. Thanks to modelling, a clear picture of processes and relationships in the modelled area can be obtained, and the information can be used to maintain a stable position on the market, to increase the competitiveness of a company, or to reduce competition risks [7]. Business model is an excellent tool which entrepreneurs can use in order to adapt their activities to new market challenges, predict the consequences as well as improve their management for risks that the influence factors cause. Awareness and assessment of the factors makes it possible to timely develop alternative scenarios and diverse approaches. New technologies create new models of interaction. These models did not exist earlier because its economics doesn't fit or there are no technological possibilities [8]. These approaches are based on the analysis of potential scenarios of positive or negative actions, which in the near or distant future may work well in practice. In the literature [9], the possibility of using them is indicated in supporting the implementation of such management methods and tools as the assessment of the product life cycle, the analysis of market scenarios, the analysis of the marketing mix etc. [10]. But what factors are influencing Fintech themselves? What risks a FinTech company has to be prepared for to manage and mitigate? Which of them must be qualitatively and timely managed to ensure the sustainability of the business model? Which of them effect the business model disruptively and which provides the company new opportunities? The influencing factors have been discussed as part of the literature review has different influence on company's willingness to innovate its business model. Some of them act as drivers and stimulate companies to be more innovative, and others hinder innovation capabilities and consequently act as barriers [7].

The aim of this research is to find out what and how microeconomic factors affect business modelling of the FinTech companies.

In this research authors used a continuous comparative analysis method, sing open coding, level 2 coding, axial coding and content analysis method with inductive and deductive approach as well as content analysis method [2].

To achieve the goal the authors interviewed the Print ISSN 1691-5402 Online ISSN 2256-070X http://dx.doi.org/10.17770/etr2019vol1.4125 (C) 2019 Rosita Zvirgzdina, Helena Skadina, Iveta Linina. Published by Rezekne Academy of Technologies. This is an open access article under the Creative Commons Attribution 4.0 International License. 
representatives of different FinTech companies. In these interviews, experts were asked to describe the most significant microeconomic risks focused on the company's business modelling and to assess the importance of them for each business model dimension by using the Likert's scale as well as to explain the dependencies and the consequences of their influence on different business model areas.

As a result of the research, these risks were arranged by the level of importance based on the expert's assessment. This aspect points out what risks must be paid particularly attention to by modelling business in Fintech; the difference of their influence and dependencies was determined. This aspect indicates possible consequences of the impact on FinTech company's business model and shows the week areas of business model dimensions which should be analysed appropriately while business modelling in order to timely manage them while implementing and working on international markets;

The result of this research forms the basis for conclusions about the most significant microeconomic risks and their impact on dimensions of an business model as well as makes recommendations possible for those FinTech-enthusiasts who are going to model their FinTech business internationally.

The tasks of the research are: to study the theoretical aspects of the concept of a business model; to define the most common microeconomic impact factors for each business model dimension that are crucial for modelling of an internationally operating FinTech business and determine those business model dimensions which are affected by the microeconomic impact factors the most, or rather, have to be taken into account by modelling business of a FinTech company.

Various methods were used in the research: the theoretical part consists of the scientific literature analysis. Semi-structured interviews with 3 FinTech experts (OC, $\mathrm{MR}, \mathrm{PB}$ ), representing the FinTech industry (E-Money Institution (EMI)) of Malta (OC), short-term lending company (PLK) of Russia (MR) and Payment Institution of Great Britain (PB), were conducted during the course of the research. The research data was processed by continuous comparative analysis, using open coding, level 2 coding, axial coding and content analysis method with inductive and deductive approach [2].

In interviews, experts were asked to describe the most significant risks focused on the company's cross-border activity and to assess the importance of them for each business model dimension by using the Likert's scale with points 15 , where 1 - irrelevant; 2 - unimportant; 3 - moderate; 4 - important; 5 - very important. as well as to explain the dependencies and consequences of their influence on different business model areas.

The data is presented in the form of a diagram. The choice of experts was based on the diversity of their expertise ( $\mathrm{OC}-10$ years, $\mathrm{PB}-20$ years, $\mathrm{MR}-4$ years). The companies represented by experts are completely different and unrelated to each other.

\section{MATERIALS AND METHODS}

Until now there is no consistent theoretical approach to the concept of a business model in the literature: it can be concluded that a business model is a logical and contemplated interplay of company's decisions, business activities and participants, which describes the place, the time and the reason of business [11]; the benefits for customers and partners [12]; the ways in which customers and partners benefit [13]; the mechanism of service creation and participants in its provision [14]; the way in which the benefit translates into profit [13]; profit reallocation way [15] and the involvement and placement of technologies to create company value and promote the operational efficiency of the company [16].

Entrepreneurship in FinTech branch starts with the launch of a new start-up and with the idea of like-minded people, pursuing the purpose to provide services that customers have never received from banks. This means that FinTech has certain startup characteristics: “... innovative nature of the product or service; ... established by a team of multiple members; ... a common tendency to create business logic that nobody has ever had ... because everything is being neglected" [17]. A business model is at the core of any successful startup, because no matter how good or unique an idea may seem, "a startup must have a viable way of making money that is worthy enough for future investment and to sustain itself" [18]. Questions like "What business model works best with my idea?" or "How do I know if my startup is using the right model?" are a few questions founders need to consider which will ultimately impact the overall success of their venture in the long run. "The business model needs to tie to the consumer pain point and work better than the competition's" [18]. The content of the business model and its robustness are the success and failure of business in the company.

The concept "FinTech" has emerged relatively recently and expresses its essence, including "... the provision of financial services through intensive use of the latest technology" (Jhoon, 2015; Song, 2015; Shim and Shin, 2016). FinTech companies operate in the financial sector alongside banks and offer their customers payments, money transfers in electronic and virtual currency. These companies are recognizable as fast lenders or peer-to-peer platforms, in which clients manage their money as well as borrow and lend it to each other. Those are securities market consultants that compete with banks by offering a high consulting level through robots. FinTech companies are not only those who offer products or services but also those who develop them.

Beyond the responsibility for building properly business models, creating functional strategies and faultless business processes, managers have to integrate, blend and skilfully present them. It is possible to better understand the thinking of business partners and their mutual fit by mapping their thoughts. A mind map can help easily transform unrelated data on the company into useful information and knowledge. Using it in the process of constructing business models it provides the possibility 
of presenting them in an attractive and interesting way, which facilitates effective communication [4].

\section{RESULTS AND DISCUSSION}

Four microeconomic factors - Supply and Demand, Labour, Production and Costs, Competition - were considered in this study as microeconomic impact factors that could play a significant role in the creation of an internationally operating business model of a FinTech company. Questions that were asked to the experts during semi structured interviews were based on these microeconomic factors. During the interviews, the authors managed to create thematic subcategories for which additional questions were asked, as well as an expert evaluation.

From all the Figures which can be seen below (Fig.1,2,3,4) it is possible to conclude that all of the examined microeconomic factors significantly influence the value creation dimension in the business model and that the value chain transforms inputs into products and services. "The customer is the recipient of the product, which is the value created by the company's transformation process" (Ramirez, 1999). The second most important dimension of the business model, subjected to factor influence, is the customer dimension.

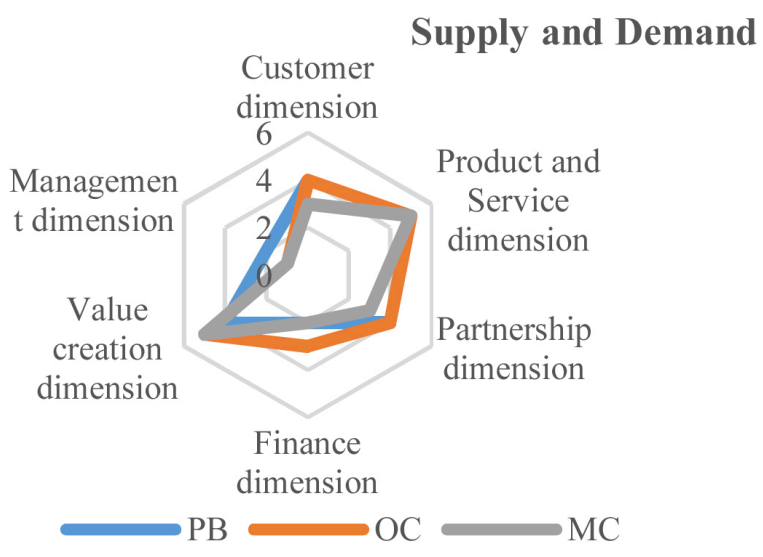

Fig. 1. Influence of Supply and Demand on business model dimensions

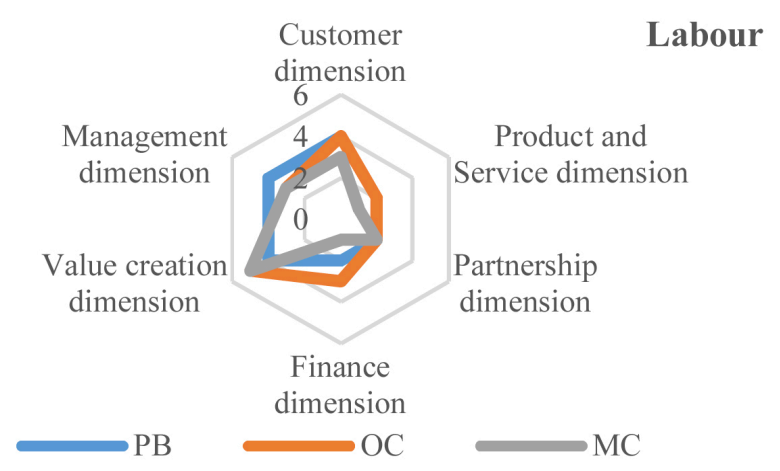

Fig. 2. Influence of Labour on business model dimensions

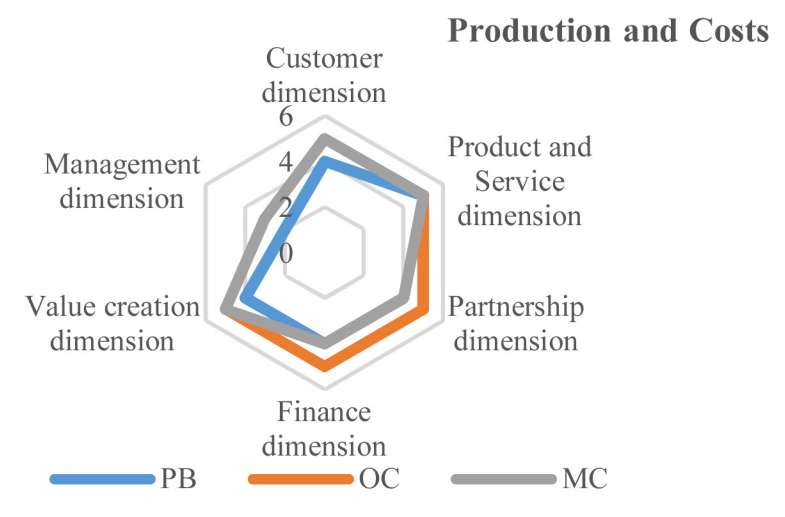

Fig. 3. Influence of Production and Costs on business model dimensions

Competition

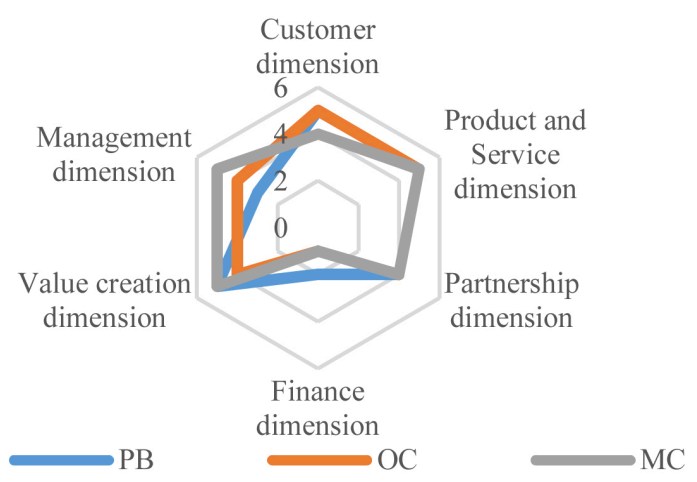

Fig. 4. Influence of Competition on business model dimensions

When developing a business model for an internationally operating FinTech company, the company must take into account that "each market will have its own customer segment for which services will be offered" (Interview with MR, 15.02.2019.). "The range of customer segments" in the market also shows "the range of communication tools needed" as well as "the choice of collaboration partners" (Interview with PB, 13.02.2019.). Based on the information provided by the experts, the company must also adapt its products and services as well as the service on each market separately. This means that a standardized and unified approach is not considered feasible. This fact also affects the financial performance of each market. The labour resources of each individual market are one of the marked aspects from the experts' point of view. The labour market "influences the choice and qualifications of the company's employees" as well as "the peculiarities of culture and language" (Interview with OC, 11.02.2019.). For example, OC emphasizes that, despite the proliferation of English, an internationally operating FinTech company must be ready to work in the local market language too "because 'it is impossible to attract the necessary programmers in English on the Serbian market" (OC). It also points at the need to adapt communication both within the company and to customers in the new market. The development of products and services and the associated costs also have a 
significant impact on the customer dimension. "If we can save on the technologies we use in all markets, we spend on labour recruitment for each market individually" (OC) The variety of sales channels, which is formed in the business model of an internationally oriented company, also means "additional expenses for maintaining the partnerships" (Interview with $\mathrm{PB}, 13.02 .2019$.). In the value creation dimension, the impact of microeconomic factors is the most significant in the authors' view. The experts appreciate this aspect the most because FinTech's basic advantage is not "the financial services they provide, but the service, speed, convenience and customer comfort through these services" (Interview with OC, 11.02.2019.). Assuming that the business model generally reflects the way in which a company creates value, the dimension of value creation could be seen as a measure of the viability and sustainability of the business model. "The twentyfirst century value creation is dominated by companies that provide global networking services of various types" (Interview with MR, 15.02.2019.).

To assess the impact of microeconomic factors on the business model's customer dimension, the authors originally asked the experts about the factors that companies must take into account while modelling their business and which affect the company's activities during the business modelling phase as well as the company's lifetime. Based on the information provided by the experts during the interviews, the authors succeeded in creating thematic categories of the most frequently mentioned microeconomic factors (Fig. 5, 6). The authors also asked the experts to evaluate these categories on Likert's scale to determine their significance and impact on each dimension of the business model. Evaluating the information provided by the experts and the frequency of words used in experts' answers, the authors were able to create a second level of thematic categories derived from the first ones. Using propitious situation and opportunity to repeat the interview with experts, the authors asked to evaluate these factors as well.

\section{Customer dimension}

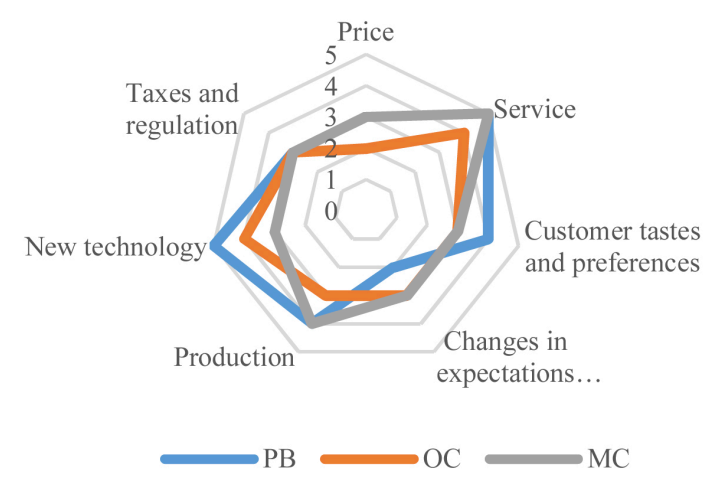

Fig. 5. Influence of microeconomic factors on customer dimension

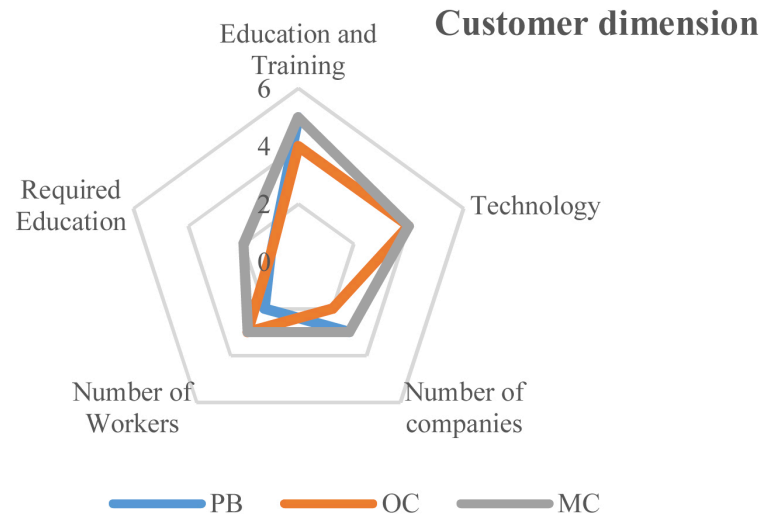

Fig. 6. Influence of microeconomic factors on customer dimension

As is evident, the most commonly discussed and analysed microeconomic factors that FinTech companies have to face when modelling their businesses are service, new technologies and a bit less pronounced - production aspect. Experts expressed unanimous opinion that the main focus of FinTech companies is "concentrated on solution" (Interview with MR, 15.02.2019.) that they offer their customers, "on service" (Interview with PB, 13.02.2019.) with which this solution is augmented and "on technologies" (Interview with PB, 13.02.2019.) that facilitate the provision of the service, "speed and convenience" (Interview with OC, 11.02.2019.) of using this service. By modelling business in the customer dimension and defining the customer segment itself, the most important factor, according to experts, is the level of service which is "mostly the only difference from other competitors with similar solutions" (Interview with PB, 13.02.2019.). "Differences can be achieved with the quality of delivered service and service delivery speed, based on technologies" (Interview with OC, 11.02.2019.). Technology is a major enabler because the company can build global delivery at scale, whilst also offering relevant data and higher delivery quality. "Financial services are not tangible, they are bought by customers considering the emotional aspect" (Interview with OC, 11.02.2019.) and only while customers are using them "they get a sense of service quality and correspondence with the price" (Interview with PB, 13.02.2019.). Relative on this, experts believe that the high level of the price does not affect the customer dimension negatively when the customer needs are satisfied and expectations fulfilled. When a company is working in a particular market niche, it has to consider and analyse "the preferences of this segment" (Interview with MR, 15.02.2019.), as "this is the only way to meet specific needs" (Interview with PB, 13.02.2019.). As for changes in customer expectations, experts believe that they are made by companies themselves, "accustoming clients the convenience of their services" (Interview with MR, 15.02.2019.). It is a kind of interaction with a client who "has to have a tendency to be positively developed while using the current service from customer" (Interview with OC, 11.02.2019.). "If the company actively appeals to the customer and sees him as a value determinant and quality assessor, constantly ensuring positively feedback regarding the service and quality, it obtains the most valuable information for improving, changing and optimizing its service" (Interview with MR, 15.02.2019.).

Experts attach great importance to training and 
qualification of staff. However, the authors found that the experts did not evaluate the education of the employees as essential. This can be explained by the fact that the qualification provided by the company must be focused on the special aspects and profile of the FinTech industry. This "can only be obtained by exchanging information with partners, participating in conferences and workshops with industry representatives" (Interview with $\mathrm{PB}, 13.02 .2019$.). This indicates that there is also great potential in the field of education for the development of new education programs. Similar factors and their impact on business model can also be seen in the product and service dimension (Fig. 7, 8) where the employee training is assessed as very important as well. However, with regard to the required education, the opinions of experts differ. These differences can be explained by the fact that FinTech also employs financial specialists and analysts who are required to have the necessary education and whose job responsibilities are slightly different from those of other companies. With regard to the number of companies as an impact factor, experts consider it to be of moderate importance. According to OC, "market participants always differ from each other and try to create a supply for certain customer needs" (Interview with OC, 11.02.2019.). On the other hand, PB notes that "the big number of competitors has a positive influence on stimulating demand and cooperation between competitors and on creating a new service as a symbiosis and innovation in the market" (Interview with PB, 13.02.2019.).

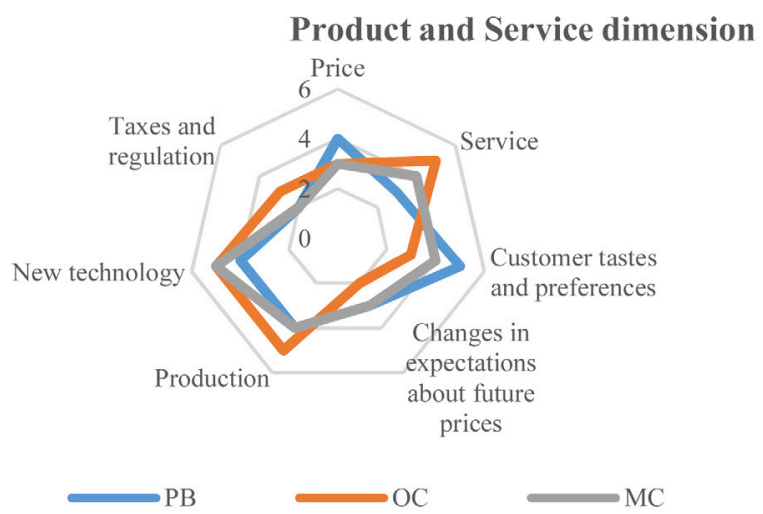

Fig. 7. Influence of microeconomic factors on Product and Service dimension
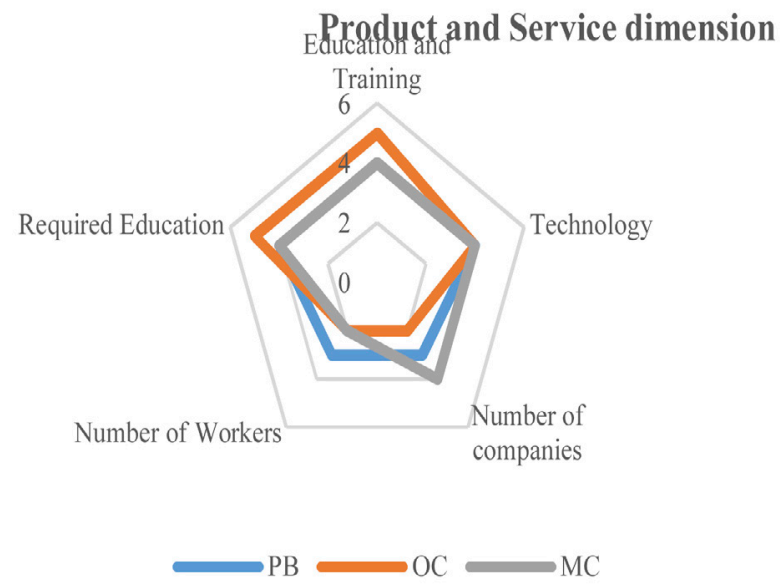

Fig. 8. Influence of microeconomic factors on Product and Service dimension
In terms of offered products and services, experts distinguished the great importance of the technologies used within the company. However, technology development in the company was assessed differently. MR believes that when it comes to development of a technological solution, the company tries to create a unique and unprecedented solution that includes both service features and competitive advantages. OC, in turn, believes that technology needs to be borrowed from competitors or co-operation partners, as it is possible to balance the financial aspect of the business model and the uniqueness is the service that complements this solution. With regard to customer tastes and expectations about the produced products and services, experts believe that this aspect is not a problem for FinTech companies, and the potential for customer expectations regarding technological financial solutions is still not exhausted, because the largest competitors of FinTech companies are banks where this aspect is not taken into account almost at all.

Speaking about the next business model dimension - the partnership dimension (Fig. 9, 10), experts unanimously pointed the importance of the number of similar companies in the market. OC expressed the view that "there are still too little companies on the market and the choice of partners is difficult" (Interview with OC, 11.02.2019.). "There is nothing to choose from when it comes to something specific". "Those who are in the market offer the price that should be used" (Interview with OC, 11.02.2019.). MR also noted the lack of cooperation partners working in the Kazakh market. "It also has a negative impact on the quality of provided services" (Interview with MR, 15.02.2019.).

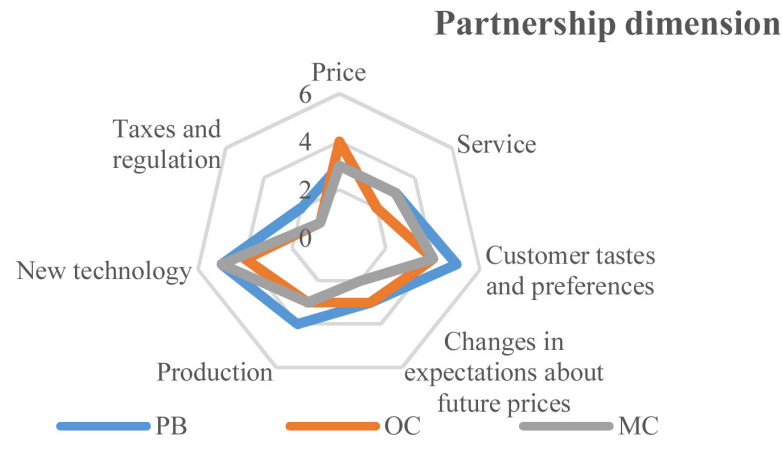

Fig. 9. Influence of microeconomic factors on partnership dimension

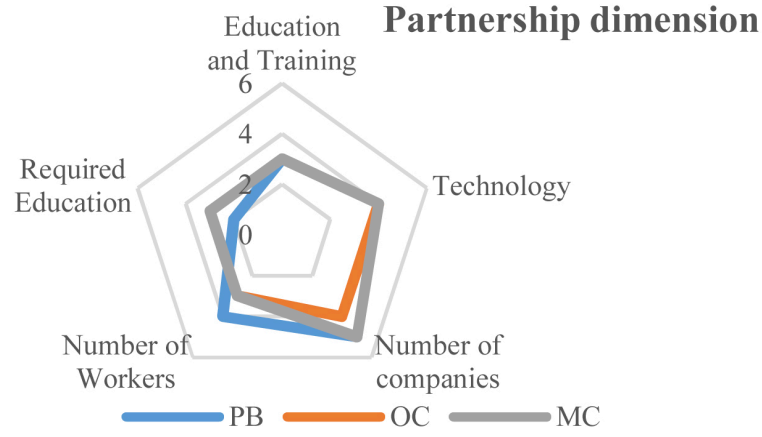

Fig. 10. Influence of microeconomic factors on partnership dimension 
If a business model is set up to work in different markets, the company must be aware that the way to reach customers will be different in each market. The size of the market is also very important because it determines both the quantity and the habits of both consumers and competitors. Each market also determines the variety of partners that will be used to deliver the product to the end customer. "With each new market, new sales channels also appear and the bid price changes" (Interview with $\mathrm{PB}, 13.02 .2019$.). In order to remain competitive, it is also necessary "to provide for a lower bid that will be presented for each stage of the service" (Interview with $\mathrm{PB}, 13.02 .2019$.). It has to be understood that "the cost of running a business with partners will always be lower in sales and marketing costs than working and maintaining direct relationships with the customer" (Interview with MR, 15.02.2019.). From this point it can be concluded that lower price does not necessarily mean lower profit for the company.

No thematically categorized microeconomic factor that was created by the authors and based on the texts provided from the experts was given a particularly great impact on the partner dimension. Working on new products or improving existing ones or customizing customer needs - the choice of partners is crucial but "the company always has the opportunity to seek for solutions around the world" (Interview with OC, 11.02.2019.). Working in a market where the choice of partners is still poor "partnership prices are more meaningful" (Interview with PB, 13.02.2019.). According to OC, "the price at which a partnership is possible is inflexible" (Interview with OC, 11.02.2019.).

After evaluating expert opinions about the financial dimension of the business model, the authors can conclude that all the microeconomic factors that were considered and evaluated during the interviews have a significant impact on the financial aspect (Fig. 11, 12).

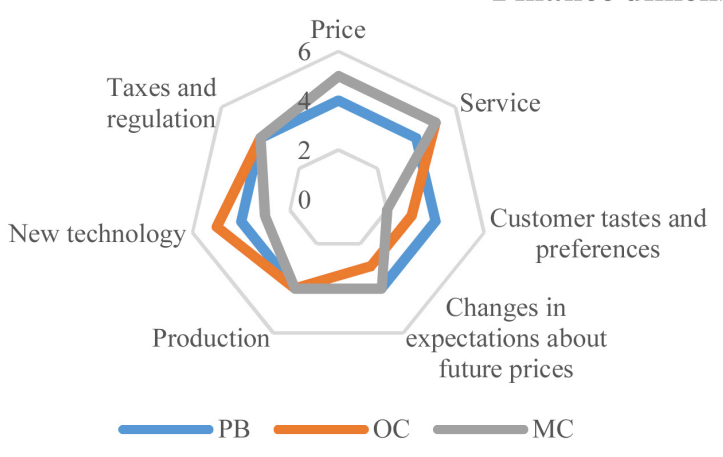

Fig. 11. Influence of microeconomic factors on finance dimension

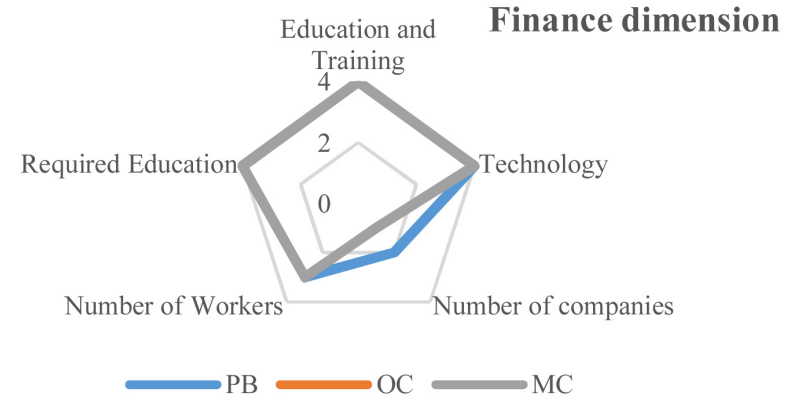

Fig. 12. Influence of microeconomic factors on finance dimension

In terms of financial resources, the company must anticipate both sales-related expenses when entering new markets and the overall market acquisition budget. It is not possible to clone a business model to each country completely. "The needs and expectations of customers in financial services are those that differ from one market to another" (Interview with MR, 15.02.2019.). They determine both the communication channels through which the customer has to be attracted and the sales tools that the customer is used to in the relevant market, as well as the culture of technology use in each market. For example, MR notes that "Kazakhstan does not need very high technology to achieve significant results, as customers are not used to using it in the financial industry" (Interview with MR, 15.02.2019.) and, subsequently, they have to be brought to them. For the technology used by the company in order to manage information and customer knowledge, the situation looks very different. "We can surprise our customers with the very fast delivery of customer services" (Interview with OC, 11.02.2019.).

Product value offer can meet the needs of consumers at a given moment. If the market is exhausted, "it is possible to offer another product value by changing the product slightly or finding another application" (Interview with PB, 13.02.2019.). While thinking about the value creation and the value of a product, it is necessary to understand what resources it requires, what distribution channels will be useful, how the relationship with the customers will be provided, what the product will be (Fig. 13, 14). If the entrepreneur is lucky and has a lot of resources, then all the ideas can be realized, but in times "when the entrepreneur is limited in resources, he has to think how to achieve the best result in such situation. At this time, creative thinking and other views are often helpful"

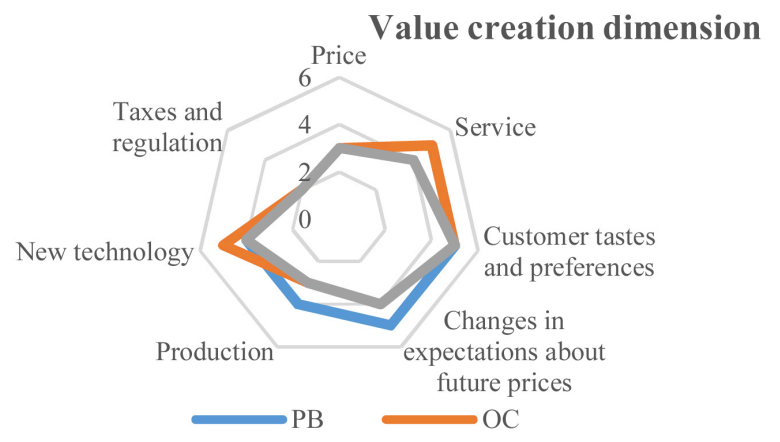

Fig. 13. Influence of microeconomic factors on finance dimension 


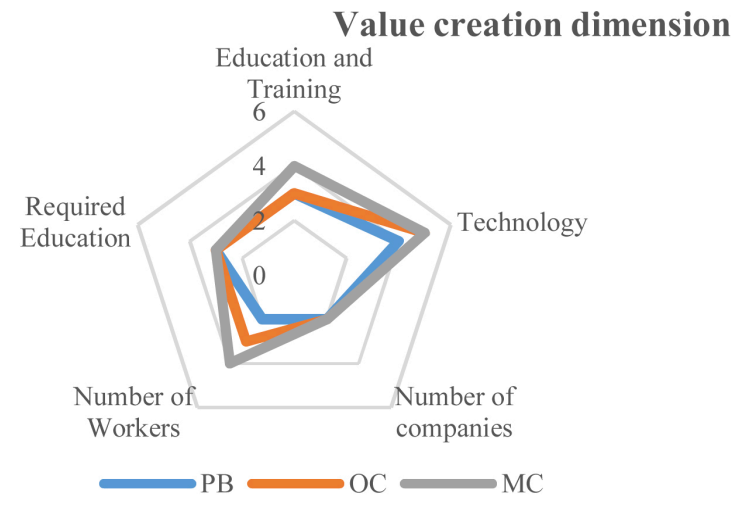

Fig. 14. Influence of microeconomic factors on finance dimension

"Our greatest value in the company is the customer's desire to use our service even more and to recommend us as a service provider to other potential customers" (Interview with OC, 11.02.2019.). "By using the right technology tailored to the needs of the company and customer requirements, the company can deliver targeted activity in its market segment" (Interview with MR, 15.02.2019.). In order to assess what technology is needed for a company, the "strategic and future-oriented assessment of market potential of a company is crucial" (Interview with PB, 13.02.2019.), as changes can occur in the market during the introduction of new technology in the company, which "makes this technology invalid on a particular demand" (Interview with MR, 15.02.2019.). Experts emphasize the importance of technology and the role of cooperation partners on the market, precisely in the dimension of value creation. This fact indicates that if a company wants to be successful in the long term, it needs to work with other market players. This is necessary to create service innovations, to exploit existing technologies in the marketplace and to jointly predict the market potential that still exists.

The above mentioned is closely related to the management of the company, which "influences the success of the business model with its quality" (Interview with PB, 13.02.2019.). Any wrong decision can negatively affect the success and sustainability of the business model in the market. The most important management role, according to experts, is "the strategic vision of the future and the ability to retain employees in the company" (Interview with OC, 11.02.2019.). Employees can be held by involving them in the decision-making process (Fig. $15,16)$.

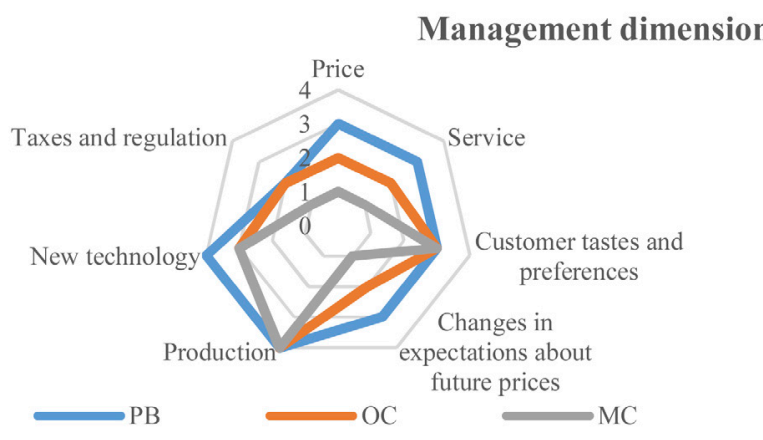

Fig. 15. Influence of microeconomic factors on Management dimension

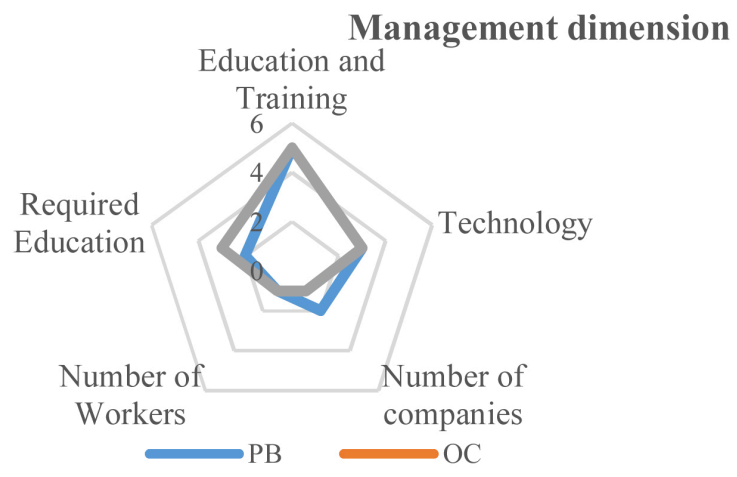

Fig. 16. Influence of microeconomic factors on Management dimension

\section{CONCLUSIONS}

All of the examined microeconomic factors significantly influence the value dimension in the business model, because the value chain transforms inputs into products and services. Assuming that the business model generally reflects the way in which a company creates value, the value dimension could be seen as a measure of the viability and sustainability of the business model.

The company must also adapt its products and services as well as the service on each market separately. This means that a standardized and unified approach is not considered feasible. This fact also affects the financial performance of each market.

The labour resources of each individual market are one of the marked aspects. The labour market influences the choice and qualifications of the company's employees as well as the peculiarities of culture and language. Despite the proliferation of English, an internationally operating FinTech company must be ready to work in the local market language too. It also points at the need to adapt communication both within the company and to customers in the new market.

Technology is a major enabler because the company can build global delivery at scale, whilst also offering relevant data and higher delivery quality. Financial services are not tangible, they are bought by customers considering the emotional aspect and only while customers are using them "they get a sense of service quality and correspondence with the price.

The qualification provided by the company must be focused on the special aspects and profile of the FinTech industry. This can be obtained by exchanging information with partners, participating in conferences and workshops with industry representatives. This indicates that there is also great potential in the field of education for the development of new education programs.

If a business model is set up to work in different markets, the company must be aware that the way to reach customers will be different in each market. The size of the market is also very important because it determines both the quantity and the habits of both consumers and competitors. Each market also determines the variety of partners that will be used to deliver the product to the end customer. It has to be understood that the cost of running a business with partners will always be lower in sales and marketing costs than working and maintaining direct 
relationships with the customer. From this point it can be concluded that lower price does not necessarily mean lower profit for the company.

Working on new products or improving existing ones or customizing customer needs - the choice of partners is crucial but the company always has the opportunity to seek for solutions around the world. Working in a market where the choice of partners is still poor partnership prices are more meaningful. This fact also affects the financial performance of each market. The price at which a partnership is possible is inflexible.

In terms of financial resources, the company must anticipate both sales-related expenses when entering new markets and the overall market acquisition budget. It is not possible to clone a business model to each country completely. The needs and expectations of customers in financial services are those that differ from one market to another. They determine both the communication channels through which the customer has to be attracted and the sales tools that the customer is used to in the relevant market, as well as the culture of technology use in each market.

By using the right technology tailored to the needs of the company and customer requirements, the company can deliver targeted activity in its market segment. In order to assess what technology is needed for a company, the strategic and future-oriented assessment of market potential of a company is crucial, as changes can occur in the market during the introduction of new technology in the company, which makes this technology invalid on a particular demand.

Experts emphasize the importance of technology and the role of cooperation partners on the market, precisely in the dimension of value creation. This fact indicates that if a company wants to be successful in the long term, it needs to work with other market players.

Management of the company influences the success of the business model with its quality. Any wrong decision can negatively affect the success and sustainability of the business model in the market.

\section{REFERENCES}

[1] K. Martinsone, A. Pipere, D. Kamerade, "Petniecība. Teorija un prakse": Research. Theory and praxis, Riga, 2016, pp. 375.

[2] Statista, Value of global investment in Financial Technology ventures in 2013 and 2018 (in billion U.S. dollars) [Online]. Available: https://www.statista.com/statistics/412056/global-investment-infintech-companies/ [Accessed Februar 18, 2019].

[3] The future of FinTech and banking: Digitally disrupted or reimagined? New research reveals three key themes for banks wanting to disrupt their own business model and reimagine themselves digitally, [Online]. Available: https://www.accenture.com/US-EN/ INSIGHT-FUTURE-FINTECH-BANKING [Accessed Februar 12, 2019]
[4] A. Jablonski, "Business Models : Strategies, Impacts and Challenges". Hauppauge, New York: Nova Science Publishers, Inc., 2017, pp. 3-17.

[5] G. Quattrone, S. Nicolazzo, A. Nocera, D. Quercia, L. Capra. "Is the Sharing Economy about Sharing at All?" A Linguistic Analysis of Airbnb Reviews. Middlesex University, London. University Mediterranea of Reggio Calabria, Italy. Nokia Bell Labs Cambridge. University College, London. Proceedings of the Twelfth International AAAI Conference on Web and Social Media, ICWSM 2018, pp.1-3

[6] Beyond fintech: "Eight forces that are shifting the competitive landscape. Impact Fintech or Fintech Impact?" [Online]. Available: https://www2.deloitte.com/content/dam/Deloitte/us/Documents/ financial-services/us-fsi-beyond-fintech-eight-forces-that-areshifting-the-competitive-landscape.pdf, 2018 [Accessed Februar 12, 2019]

[7] S. Škapa, "Solving microeconomic model using methods of functional analysis". Economic Computation and Economic Cybernetics Studies and Research. Vol. 52 DOI: 10.24818/18423264/52.1.18.05. Brno University of Technology. 2018, pp. 41-43.

[8] V. Enev, W-C Liao, "Business Model Innovation and Factors influencing. Business Model Innovation". School of Economics and Management, Department of Business Administration, Master Corporate Entrepreneurship and Innovation. Internship and degree project (Master thesis 15 ECTS). 2014, pp. 4-8.

[9] K. Berlinskii, "Problems, trends, and growth points in FinTech". [Online]. Available: https://magazine.fintechweekly.com/articles/ problems-trends-and-growth-points-in-fintech. 2018 [Accessed Februar 19, 2019].

[10] D. Mitchell, C. Coles, "The Ultimate Competitive Advantage of Continuing Business Model Innovation”. 2003, pp. 16- 26.

[11] D. R. A. Schallmo, "Geschaftsmodelle erfolgreich entwickeln und implementieren" (Successful Development and Implementation of Business Modells). Kindle Edition. 2003, pp. 1142-1557.

[12] O. Gassmann, K. Frankenberger, M. Csik, "Geschaftsmodelle entwickeln 55 innovative Konzepte mit dem St. Galler Business Model Navigator" (Developing of Business Models 55 innovative approaches with St. Galler Business Model Navigator). Munchen: Hanser Verlag, 2013, pp. 4.-213.

[13] K. Matzler, "Digital Disruption: Wie Sie Ihr Unternehmen auf das digitale Zeitalter vorbereiten" (How to prepare Your enterprise for digital age). Kindle Edition. 2016, pp. 964-972.

[14] V. Tiberius, Ch. Rasche, Ch. "FinTechs: Disruptive Geschaftsmodelle im Finanzsektor" (Dusruptive Business Models in Fintech industry). Springer Gabler, 2011 pp. 341.

K.Jhoon, "User's Acceptance of Mobile Fintech Service: Immersion of Mobile Devices' Moderating Effect", in: The e-Business Studies 6 (16), 2015, pp. 359-381.

[15] F. Buytendijk, T. Hatch, P. Micheli, "Scenario-based strategy maps". Business Horizons. 2010, pp.338.

[16] D. Roam, "Narysuj swoje mysl". Wydawnictwo Helion, Gliwice. 2010, pp.28-29

[17] B. Witz, "Business Model Management, Gabler Verlag. 2010, pp. 70-73.

[18] Song, K.-S. (2015). Investigation of Business Model on Fintech Payment System, in: The e-business Studies 16 (6), pp. 65-94. 